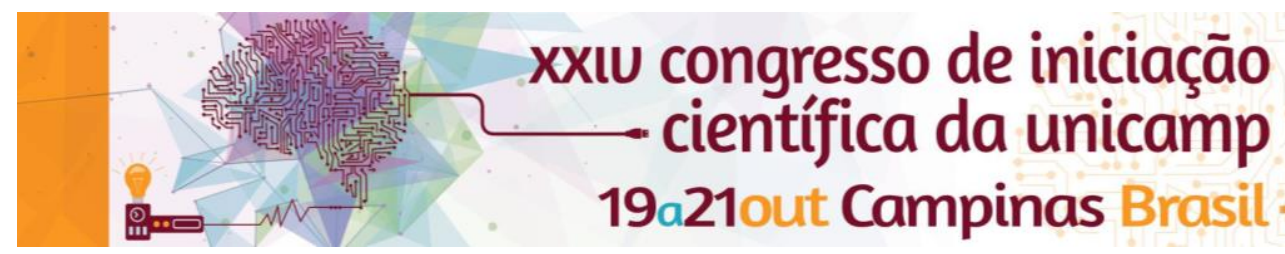

\title{
Extração de compostos bioativos da planta Conyza canadensis: comparação entre maceração e PHWE
}

\section{Lucas de P. C. Men*, Rafael S. Porto, Susanne Rath}

\section{Resumo}

A produção de frutas é comumente ameaçada por doenças pós-colheita, que em sua maioria, são causadas por fungos. Como os fungicidas sintéticos podem afetar negativamente o meio ambiente, pesticidas bioquímicos têm sido estudados. O projeto teve como objetivo extrair dois compostos antifúngicos da planta Conyza canadensis, visando comparar duas técnicas de extração: a maceração e a extração com água quente pressurizada (PHWE).

\section{Palavras-chave:}

PHWE, compostos antifúngicos, Conyza canadensis

\section{Introdução}

Em trabalho prévio, os compostos antifúngicos (4Z)lachnophyllum lactona (4Z-LL) e (4Z,8Z)-matricaria lactona (4Z,8Z-ML) foram identificados em espécimes brasileiras da planta Conyza canadensis. ${ }^{1}$

O presente trabalho teve como objetivo caracterizar estes compostos por ressonância magnética nuclear de prótons ( ${ }^{1} \mathrm{H}$ NMR) e comparar a eficiência das técnicas de extração por maceração e por água quente pressurizada (PHWE) por meio da validação de um método de quantificação destes compostos por cromatografia gasosa acoplada a espectrometria de massas (GC-MS).

\section{Resultados e Discussão}

As técnicas de extração foram bem-sucedidas em obter os compostos de interesse. Na extração por maceração, empregou-se partições com hexano (Figura 1A) e em seguida clorofórmio (Figura 1B), sendo essa última mais seletiva. O cromatograma do extrato obtido por PHWE e particionado com acetato de etila (Figura 1C) mostra seletividade semelhante à da fração clorofórmica obtida por maceração.

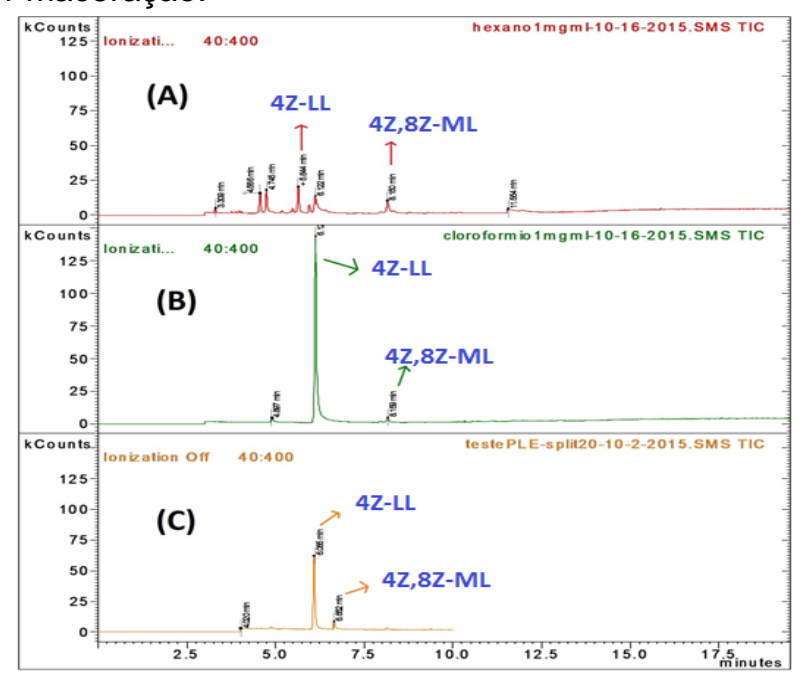

Figura 1 - Cromatogramas dos extratos de $C$. canadensis obtidos por maceração (A e B) e PHWE (C). Condições: A e B: $150{ }^{\circ} \mathrm{C}(8 \mathrm{~min})$ e 20 ${ }^{\circ} \mathrm{C}$ min $^{-1}$ até $280^{\circ} \mathrm{C}\left(5 \mathrm{~min}\right.$.), injetor $300^{\circ} \mathrm{C}$; transferline $250^{\circ} \mathrm{C}$; ion trap $180{ }^{\circ} \mathrm{C}$; Injeção $1 \mu \mathrm{L}$, split $1: 20$, gás de arraste $1 \mathrm{~mL} \mathrm{~min}^{-1}$. C: $150{ }^{\circ} \mathrm{C}$ (10 min.), injetor $300^{\circ} \mathrm{C}$; transferline $250^{\circ} \mathrm{C}$; ion trap $180^{\circ} \mathrm{C}$; injeção 1 $\mu \mathrm{L}$; split 1:20; gás de arraste $1 \mathrm{~mL} \mathrm{~min}^{-1}$. Concentração dos extratos: $1,0 \mathrm{mg} \mathrm{mL}^{-1}$.
A fração clorofórmica foi submetida a cromatografia flash para isolamento dos compostos (Figura 2), obtendo-se $117 \mathrm{mg}$ de 4Z-LL e $27 \mathrm{mg}$ de 4Z,8Z-ML. Os compostos foram submetidos a análises de ${ }^{1} \mathrm{H}$ NMR e MS, obtendo resultados que condizem com a literatura. ${ }^{2,3}$

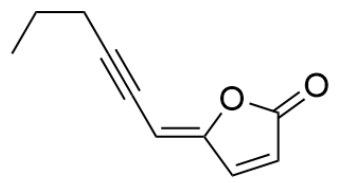

4Z-LL

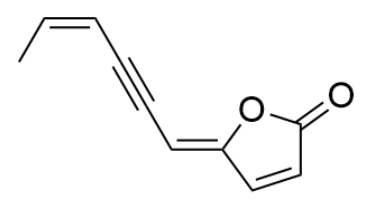

$4 Z, 8 Z-M L$
Figura 2 - Estrutura dos compostos de interesse.

(4Z)-lachnophyllum lactona $\left(\mathrm{C}_{10} \mathrm{H}_{10} \mathrm{O}_{2}\right){ }^{1} \mathrm{H}$ NMR (500 $\left.\mathbf{M H z}, \mathbf{C D C l}_{3}\right): \delta(\mathrm{ppm}) 1,06(3 \mathrm{H}, \mathrm{t}, J 7,4 \mathrm{~Hz}, \mathrm{H}-10), 1,65$ $(2 \mathrm{H}$, sext, $J 7,2 \mathrm{~Hz}, \mathrm{H}-9), 2,46(2 \mathrm{H}$, td, $J 7,1$ e $2,5 \mathrm{~Hz}, \mathrm{H}-$ 8), 5,34 (1H, t, J 2,3 Hz, H-5), 6,25 (1H, d, J 5,4 Hz, H-2), $7,39(1 \mathrm{H}, \mathrm{d}, J 5,4 \mathrm{~Hz}, \mathrm{H}-3)$.

(4Z,8Z)-matricaria lactona $\left(\mathrm{C}_{10} \mathrm{H}_{8} \mathrm{O}_{2}\right){ }^{1} \mathrm{H}$ NMR (400 $\left.\mathbf{M H z}, \mathbf{C D C l}_{3}\right): \delta$ (ppm) 7,42 (1H, d, J 5,4 Hz, H-3), 6,27 $(1 \mathrm{H}, \mathrm{dd}, J 5,4$ e $0,6 \mathrm{~Hz}, \mathrm{H}-2), 6,19(1 \mathrm{H}$, dq, $J 10,8$ e 7,0 $\mathrm{Hz}, \mathrm{H}-9), 5,75(1 \mathrm{H}, \mathrm{dm}, J 10,8 \mathrm{~Hz}, \mathrm{H}-8), 5,50(1 \mathrm{H}, \mathrm{d}, J$ $2,6 \mathrm{~Hz}, \mathrm{H}-5), 2,00$ (3H, dd, J 6,9 e 1,6 Hz, H-10).

Foi avaliada a precisão do método de quantificação para o composto 4Z-LL extraído por PHWE. Cinco replicatas de $5 \mathrm{~g}$ de planta triturada foram submetidas à extração obtendo-se concentração média de $43,14 \mu \mathrm{g} / \mathrm{mg}$ extrato, com um coeficiente de variação (CV) de 17,0\%.

\section{Conclusão}

Os compostos de interesse foram devidamente extraídos e isolados de espécimes brasileiras de $C$. canadensis. A PHWE foi eficaz na obtenção de extratos contendo estes compostos, sendo vantajosa por ser mecanizada e empregar apenas água como solvente extrator.

\section{Agradecimentos}

Agradecemos ao CNPq e à Fapesp pelo apoio.

1. Porto, R. S. Conyza canadensis: determinação de compostos bioativos e avaliação da atividade antifúngica. Dissertation, Universidade Estadual de Campinas (Unicamp), Campinas, 2015.

2. Rivera, P.; Arancibia, L.; Castillo, M., Clerodane diterpenoids and acetylenic lactones from Baccharis paniculata. J. Nat. Prod. 1989, 52 (2), 433-435.

3. Csupor-Loffler, B.; Hajdu, Z.; Zupko, I.; Molnar, J.; Forgo, P.; Vasas, A. Kele, Z.; Hohmann, J., Antiproliferative constituents of the roots of Conyza canadensis. Planta Med. 2011, 77 (11), 1183-8. 